\title{
ESTÉTICA AFRO-DIASPÓRICA E O EMPODERAMENTO CRESPO
}

\author{
Ivanilde [Ivy] Guedes de Mattos ${ }^{1}$
}

\begin{abstract}
Resumo: Tendo em vista a ocorrência nacional de diversos movimentos estéticos que identificam os cabelos como fios condutores de novas identidades, verifico as negras ousando assumir uma estética anteriormente negada e discriminada por um padrão estético de beleza eurocêntrico. Neste sentido, busco analisar este movimento enquanto fenômeno estético afro-diaspórico, considerando as ressignificações capilares com seus usos e abusos, desconstrutores de hegemonia alavancado por coletivos de mulheres negras. Esse estudo vai se concentrar em analisar como estes movimentos liderados por mulheres no interior dos coletivos instituídos através das redes sociais - via Facebook - têm contribuído para a autoestima e afirmação da estética negra a partir do empoderamento crespo e, especialmente, tornando essa afirmação estética mais uma bandeira da luta antirracista. A metodologia a ser desenvolvida está ancorada no método (auto)biográfico e na pesquisa exploratória. O referencial teórico está coadunado com o pensamento PósColonial, visto que trata-se de um estudo onde a descolonização estética é fulcral na atual conjuntura sociocultural e política do país.

Palavras-Chave: Estética Afro-Diaspórica. Empoderamento Crespo. Estima. Estigma e Mulheres Negras.
\end{abstract}

\section{THE AFRO-DIASPORIC AESTHETIC AND THE EMPOWERMENT OF AFRO FRIZZY HAIR}

\begin{abstract}
Abstratc: Taken into account the phenomenon of different aesthetic hair style movements that pin down the new identities through a variety of hair, one notes that the black women are daring to assume an aesthetic fashion previously denied and discriminated by a standard Eurocentric aesthetic beauty. In this sense, in this essay, I try to analyze this movement as African-diasporic aesthetic phenomenon considering the capillary reinterpretation with their uses and abuses, hegemony dismantling promoted by collective black women.
\end{abstract}

Keywords: Keywords: Afro-Diasporic Aesthetic. Black Empowerment. Stigma. Stigma and Black Women.

1 Doutora em Educação e Contemporaneidade (UNEB). Docente do curso de Licenciatura em Educação Física (UEFS). Membro da Comissão de Ações Afirmativas da UEFS. Líder do Grupo de Pesquisa FIRMINA: PósColonialidade, Educação, História, Cultura e Ações Afirmativas. Membro do Coletivo Vício Cacheado; Membro da Comissão da Marcha do Empoderamento Crespo de Salvador. Vice-Coordenadora da Rede de Estudos Africanos e da Diáspora (READI); Autora do livro: Estética afirmativa: o corpo negro e o ensino de Educação Física (EDUNEB). E-mail:ivyfirmina@gmail.com. 


\section{Introdução}

Com este artigo, pretendo alavancar o debate em torno da estética negra na diáspora a partir do olhar de uma mulher que esteve diretamente implicada nos processos de ressignificação desta estética desde os fins da década de 1980. Este pertencimento ao campo de estudo passa pela experiência de ser responsável por um salão de beleza na zona leste de São Paulo - caminho que foi escolhido como atuação profissional tendo em vista a dificuldade de se inserir no mercado de trabalho como recém-formada em técnica em arquitetura pelo ensino médio - o que, na época, rendeu um estreitamento relacional com o pai, reconhecido mestre de obra. Mas as limitações impuseram um redirecionamento para as habilidades com as mãos, e neste contexto, adveio a profissão de cabeleireira. Passadas algumas décadas, já professora de Educação Física, retomo esse universo de representação social do corpo negro e sua estética para avaliar como, através dos processos civilizatórios, essa estética vive a transmutação do sentimento de estigma ao de estima pelo "eu" negro com o seu corpo e o seu cabelo, atributos primordiais numa sociedade pautada no paradigma estético branco.

A estética negra pode ser considerada na contemporaneidade uma estética afirmativa? Vou ater-me a esta pergunta como problemática para o desenvolvimento de uma reflexão avaliativa sobre a Estética Afro-Diaspórica e o Empoderamento Crespo, considerando os aspectos sociais, culturais e econômicos que incidem sobre o corpo nesta sociedade descrita acima. Já há algum tempo venho descortinando esse tema no intuito de identificar o racismo e sua materialização a partir do corpo negro e seus atributos, especialmente o cabelo. Embora este texto não se trate de uma autobiografia a abordagem da pesquisa (auto)biográfica amplia as convergências entre o "ser" subalterno e acadêmico.

Inicialmente, é necessário definir o que estou denominando por Estética AfroDiaspórica, desta forma: é o movimento em que homens, mulheres, homossexuais, transexuais, gays e também as crianças negras adotam variações para os seus corpos e cabelos criando e recriando penteados de matriz africana, usando e abusando do tamanho dos fios, formas e cores, assumindo sua corporeidade nesse contexto de mudanças sociais, lutas históricas e hibridismo estético.

A pesquisa (auto)biográfica como método investigativo se dá nesse contexto marcado por uma narrativa própria. Corrobora com esse estudo o pesquisador Souza (2006, p. 25) que diz: 
As histórias de vida são, atualmente em diferentes áreas das ciências humanas e da formação, através da adequação de seus princípios epistemológicos e metodológicos a outra lógica de formação dos adultos, a partir de saberes tácitos ou experiências e da revelação das aprendizagens construídas ao longo da vida como uma metacognição ou metareflexão do conhecimento de si.

Destaco que é central demarcar o lugar de fala e a tentativa de um discurso descolonial ${ }^{2}$, cujas narrativas perpassam as múltiplas identidades nesse espaço classificado como acadêmico sem, no entanto, perder a essência do "ser" negra. Assim vamos as tessituras do método e do discurso, destacando que:

As variadas tipificações ou classificações no uso do método biográfico inscrevem se o âmbito de pesquisa socioeducacional mais como uma possibilidade de, a partir da voz dos atores sociais, recuperar a singularidade das histórias narradas por sujeitos históricos, socialmente situados, garantindo o seu papel de construtores da história individual/coletiva intermediada por suas vozes (SOUZA, p. 29).

Foram anos envolvida com cabelos e maquiagens, organização de eventos e festas. Mas cabe aqui dizer que o forte era especialmente o de alisar e escovar cabelos crespos, pois, naquela época, a busca por cabelos lisos era condição quase que determinante a uma grande parcela das mulheres negras.

O fato de eu ser negra e de ser a profissional a cuidar dos cabelos crespos naquele contexto não fez com que o meu salão de beleza fosse especializado em cuidados e tratamentos para cabelos afros/crespos. No entanto, era evidente que muitas mulheres pretas e pardas sentiam-se mais à vontade, acolhidas e/ou confortáveis em serem atendidas por uma profissional cuja etnia dialogava com as necessidades que ora emergiam, e confiavam a mim sem emissão de voz: "me deixa bonita"; "alisa meus cabelos e serei menos rejeitada esteticamente".

Quase a maioria das mulheres negras da época buscavam dominar os cabelos crespos usando os mais variados tipos de alisamentos, tais como: Henne Marú ${ }^{\circledR}$, Pasta de Alisar ${ }^{\circledR}$ Guarnieri ${ }^{\circledR}$, Touca de Gesso ${ }^{3}$, Amônia, Wellin ${ }^{\circledR}$, pente de ferro, ferro de passar roupas e co-

2 O discurso descolonial está amparado nos Estudos Pós-Coloniais que não constituem propriamente uma matriz teórica única. Trata-se de uma variedade de contribuições com orientações distintas, mas que apresentam como características comum o esforço de esboçar, pelo método da desconstrução dos essencialismos, uma referência epistemológica crítica às concepções dominantes de sociedade. Iniciada por aqueles autores qualificados como intelectuais da diáspora negra ou migratória, fundamentalmente imigrantes oriundos de países pobres que vivem na América Ocidental e na América do Norte, a perspectiva póscolonial teve na crítica literária Inglaterra, sobretudo na Inglaterra e nos Estados Unidos, a partir dos anos 1980, suas áreas pioneiras de difusão (COSTA, 2006, p. 83).

3 Touca de gesso é um processo químico com a seguinte composição: líquido para permanente; creme para hidratação e farinha de trigo. Depois de aplicado no cabelo seco aguarda o endurecimento da pasta que deve ficar com a consistência de gesso. Depois de retirado os fios ficam alisados. 
quinhos, os quais exigiam verdadeiros rituais, como: alisar, lavar, enrolar bobes, puxar os fios na escova com secador muito quente e fazer touca (ou nero).

Foi um tempo de sacrifício e resignação para muitas mulheres manipuladas pelos modelos estéticos em voga, que se submeteram a um enquadramento estético, devendo estar o mais próximo do ideal de branquitude ${ }^{4}$. A construção da frase nos remete ao passado porque, para avaliar os processos civilizatórios e a desconstrução dos parâmetros estéticos eurocêntricos, temos que retomar um período histórico cujas possibilidades de inversão de valores e normativas sobre o corpo negro eram mínimas, e alisar os cabelos seria uma sentença, ou seja, uma prioridade para o universo feminino como "catalisador” de inclusão social.

Na contemporaneidade, podemos vislumbrar um outro tempo, não menos racista e discriminatório, mas de uma diversidade estética mais contemplativa, em que principalmente se observa a insurgência dos cabelos crespos e naturais numa nova construção de estima e pertencimento. O caminho a ser percorrido para a coleta de dados será concentrado nas páginas do Facebook especificadamente os grupos virtuais, bem como imagens públicas disponibilizadas pela Internet referentes ao protagonismo negro em diferentes redes de propagandas. Pretendo eleger como referencial teórico principal os Estudos Pós-Coloniais entendendo que o campo a ser investigado requer uma postura de enfrentamento ao colonialismo acadêmico.

\section{Cabelo ruim!}

É comum dizer que o cabelo crespo é um cabelo ruim. Historicamente, o corpo negro carrega o estigma da cor. Entre o que é "bom" e o que é "ruim", recaem sobre o corpo do negro todas as imposições do que é negativo. Ser negro no Brasil é ser condenado a um juízo de valor no qual a cor da pele e a textura do cabelo classificam o grau da discriminação.

O corpo humano e seu fenótipo forneceram os dados a partir dos quais foram formuladas teorias que escalonaram os seres humanos. Delegaram às chamadas raças brancas o lugar de paradigma de beleza, o ápice da pirâmide estética e relegou às raças não brancas, especialmente a negra, a base da sua hierarquização — pode-se citar outras esferas da hierarquização como as das qualidades morais e intelectuais. Neste sentido, percebemos que características físicas são lastro, substrato material de

4 Tomo como referência o conceito de branquitude para definir o contexto em que a educação serviu aos interesses da elite burguesa para degeneração da negritude. De acordo com Dávila (2006, p. 24), em Diário de Brancura, "As escolas que eles criaram foram projetadas para imprimir sua visão de uma nação brasileira ideal, naquelas crianças sobretudo pobres e não-brancas que deveriam ser a substância daquele ideal”. 
qualquer processo de construção identitária, especialmente num jogo imbricado onde raça, cor e estigmas misturam-se e colocam os negros em severas desvantagens representacionais (GOMES, 2015, p. 8).

Leituras como as desta autora nos permitem identificar como emergiu a ciência estética ainda no século XVIII, e que resultou em teorias racistas, aniquilando toda e qualquer estética fora do padrão. Foucault (1997) corrobora quando identifica na genealogia do racismo a exclusão dos corpos negros das instâncias de poder. A eugenia, por sua vez, tratou de classificar a raça negra como uma maldição que deveria ser afastada e, de alguma forma, eliminada como figura humana.

A eugenia foi uma tentativa científica de "aperfeiçoar" a população humana por
meio do aprimoramento de traços hereditários - noção popular por toda a Europa e
Américas no período entre guerras [...] Uma eugenia "pesada" baseada na remoção
do acervo reprodutivo de indivíduos que possuíam traços indesejados por meio da
esterilização ou do genocídio foi aplicada em diversos graus em países como a Ale-
manha Nazista, a Grã-Bretanha e os Estados Unidos. Essa variedade de eugenia
combinava bem com as ideias sobre raça defendidas pelas elites brasileiras que ad-
mitiam a inferioridade dos pobres e não-brancos e ainda assim buscavam a possibi-
lidade de recuperar essa população e, consequentemente, a nação (DÁVILA, 2006,
p. 31-32).

Enquanto obstáculo para o projeto de nação, os representantes da burguesia se encarregavam de branquear sujeitos cuja cor da pele estivesse mais para a parda e deixar os cabelos menos crespos e armados, denominados de mestiços. Assim, a sociedade foi-se constituindo e hierarquizando as relações de poder.

Desde então, a discriminação racial afeta as subjetividades de negros e negras, escravizados ou libertos. De forma mais agressiva, àqueles de pele mais escura, cabelos crespos ou carapinhas nesse caso os mais pegado no couro cabeludo sem cachos definidos, de expressões menos harmônicas, segundo categorias eugênicas, como: peso, altura, nariz achatado, orelhas de abano (abertas) e testas largas. Estigmatizados, homens, mulheres e crianças negros são forçados a constituírem novas formas de socialização como enfrentamento das coerções físicas e simbólicas que perduram ao longo da história da civilização humana.

Destaca-se que, mesmo durante o período de escravidão no Brasil, os negros não aceitaram passivamente serem discriminados e subjugados. De acordo com Wilson Mattos (2013), no livro "Negros contra Ordem", a história da escravidão não pode silenciar as revoltas e fugas que resultaram em muita dor e sofrimento, mas, também, efetivamente, em consolidação de comunidades negras resistentes. É fato que ao longo da história, com a libertação dos escravos ao final do século XIX, alguns negros foram agregados aos seus antigos donos em outra condição, como negros libertos; outros se autonomizaram, e outros tantos se revoltaram 
contra seus antigos senhores e malfeitores. Com a falta de interesse da burguesia pela mão-deobra de escravos libertos, a sociedade brasileira se viu entre maioria negra, dado o contingente de homens e mulheres livres ocupando as cidades, ruas e praças.

Os ajustes sociais e econômicos para a inclusão dos negros na sociedade em nenhum momento foram pauta dos nacionalistas de direita preocupados prioritariamente com um perfil de nação mais voltado para a indústria e alicerçados por um corpo higienicamente saudável, vigoroso e disciplinado. Com isso, mantinham os negros às margens desse ideal de "nação", e as consequências sentenciaram as populações negras descendentes de escravos às mais duras experiências de sobrevivência em uma sociedade altamente racista e excludente, criando um abismo socioeconômico e perdas culturais muito caras para os diferentes grupos étnicos vindos do continente africano. Utilizo o termo "perdas" porque talvez nem os antropólogos, etnólogos ou historiadores tenham tido acesso às bagagens culturais que, por condições de sobrevivência nas Américas, foram rapidamente sucumbidas e estrategicamente ocultadas.

A intenção aqui é avaliar a partir da dimensão estética os prejuízos que a colonização severamente sentenciou mulheres e homens negros - estética essa ultrajada as formas consideradas desarmônicas pela burguesia branca. A cor da pele e os cabelos foram desde então os elementos mais estigmatizados da estética negra. Cabelos crespos eram rotulados de "cabelo ruim" e os de pele mais escura, adjetivados como "negros fedidos" e "feios". Em estudo anterior, apresento um recorte sobre a eugenia no Brasil, destacando o papel do psicólogo Dr. Renato Khel, um dos maiores divulgadores da eugenia e articulador da rede formada por representantes da elite burguesa adotando a seguinte linha:

[...] políticas higienistas e eugenistas embasaram várias medidas de segregação racial. Uma delas, por exemplo, se efetivou através da estruturação do espaço geográfico, limitando as áreas de confluência entre os corpos considerados belos e saudáveis e a plebe rude, com seus corpos maltrapilhos e doentes. Provavelmente, a formação dos bairros foi pensada politicamente para a separação higiênica e social, afastando desta forma a pobreza para bairros distantes (MATTOS, 2009, p. 46).

Foi desse modo que o Brasil se desenvolveu, negando aos corpos negros condições de sociabilidades ou interações com os processos de civilização em igualdade de oportunidades entre negros e brancos. Ainda que o projeto de "nação" tenha tentado invisibilizar a população negra, a história sobre o fim da escravidão quantifica que o número de negros livres surpreendeu/frustrou os mais entusiastas de um Brasil ocidentalizado - branco. As presenças negras se fizeram permanentes: seus cabelos armados, trançados ou alvoroçados; seus beiços largos, 
narizes achatados e testas grandes; o modo de andar desenvolto e as ancas avantajadas conflitaram as cenas urbanas desde o final do século XIX até os dias de hoje.

Figura 1 - Cena urbana

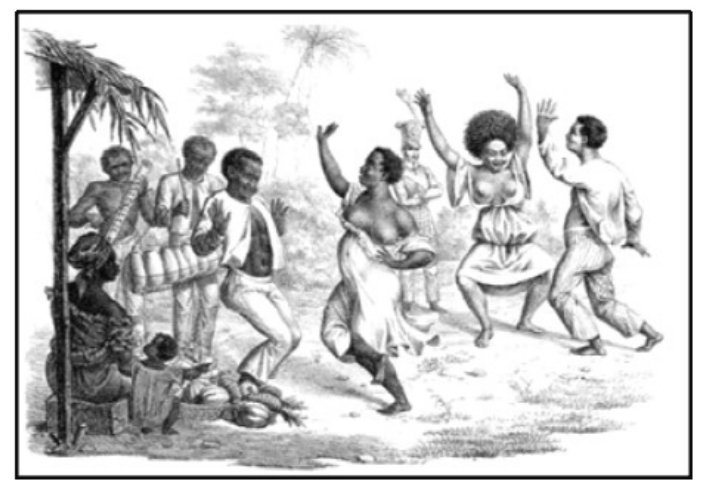

Fonte: raizdosambaemfoco.wordpress.com

\section{Cabelo alisado}

Atenho-me agora a reflexões mais contemporâneas sobre a estética negra, dado o fenômeno da volta aos cabelos naturais/crespos, sem perder de vista as experiências vividas nesse campo, quando como profissional da beleza que, por alguns anos, manipulou os cabelos de muitas mulheres negras a fim de vê-los mais lisos e menos volumosos através de diferentes químicas capilares, como já fora esclarecido. Ressalto que, neste tempo, eu já militava no movimento negro do meu bairro, o "Cangaíba", no grupo Senzala. Inclusive, muitas mulheres do grupo tinham seus cabelos alisados, o que não era necessariamente um problema para o debate sobre questões relacionadas ao preconceito e discriminação, e as ações desenvolvidas pelo grupo naquele contexto — anos 1980.

O fato de algumas alisarem os cabelos não as fazia menos negras do ponto de vista da consciência de raça, o mesmo se dava na minha atuação profissional. Inclusive, o próprio espaço profissional serviu para a realização dos encontros do grupo que, na época, não tinha sede própria nem local fixo para as reuniões. Cabe dizer que as preocupações naquele contexto eram conjugadas a partir de várias demandas, sobretudo política, pois estávamos envolvidos

5 Cangaíba é um bairro de periferia da Zona Leste de São Paulo. 
com organizações partidárias reivindicando estruturas para a comunidade pobre e negra do Cangaíba.

É histórico que os negros para serem aceitos nos espaços sociais e do mercado de trabalho eram diretamente influenciados pelos padrões estéticos que beneficiavam aqueles mais próximos da estética branca. Daí o alto contingente de mulheres negras com cabelos alisados. Aliás, muitas destas mulheres sofreram ojeriza aos seus cabelos crespos, vítimas de preconceitos, principalmente no início da escolarização, quando as relações se dão coletivamente e a diferença étnico-racial se torna um agravante. Considerando que os indivíduos com a pele mais escura e os cabelos mais crespos eram alvos recorrentes de piadas e chacotas em ambientes fora do convívio familiar, é possível compreender a busca desenfreada para minimizar o que mais evidenciava estar "fora" dos padrões socialmente aceitáveis.

Vi de perto como o racismo destrói subjetividades: mulheres com baixa autoestima, escravas dos alisamentos, tiveram perdas capilares irreparáveis, e muitas foram e são preteridas dado o aspecto considerado mais negroide. Estudos sobre autoestima de mulheres negras revelam o poder do racismo sobre vidas humanas que sofrem, às vezes, isoladas de tal maneira, que chegam à morte. Entretanto, pouco se avalia no campo da saúde o racismo como mal de séculos ou como um problema de saúde pública. Se dados fossem levantados sobre o alto índice de doenças decorrentes do racismo, provavelmente o número de mulheres negras em depressão por consequência de tentativas frustradas de alisamento dos cabelos ganharia posição de destaque.

A militância nesse aspecto me permitiu muitos avanços. Foi dentro destaa que tive minhas mais fundantes lições de solidariedade e irmandade - o que a escola não deu conta enquanto conhecimento sobre a história dos negros e a escravidão no Brasil - lá foram dados objetivando desvelar o racismo nas suas diferentes esferas e uma delas é, certamente, a dimensão estética, pois são mais de quinhentos anos de negação dos elementos mais visíveis que compõem a estética negra: cor da pele e cabelo.

Hoje, como estudiosa do campo das relações raciais, posso afirmar que vivemos um tempo de ressignificação da estética negra. Ouso dizer que há uma reparação dos elementos identitários, anteriormente negados, como signo de uma bandeira de luta liderado pelas mulheres negras em sua maioria. Tomo como campo empírico desta análise os grupos formados 
por mulheres nas redes sociais onde tem se consolidado pela "Sororidade" caminhos para inscrição da filosofia Ubuntu. Define a pesquisadora Suely Gomes Costa (2004, p. 4):

Os feminismos, em algum momento de sua história, criaram e propagaram, como expressão de sua identidade, a noção de "sororidade" ou da irmandade, a ideia é força de unificação das mulheres, admitidas como iguais em sua biologia, aglutinadora de energias numa luta comum contra a desigualdade em relação aos homens. Afirmada no poder social das mulheres, visível nos "maternalismos", lugares das lutas feministas por direitos sociais ${ }^{7}$. Essa forma de pensar a identidade biológica ganha revisões a partir dos anos 80 , do século XX. Na noção de "sororidade", conformamse a homogeneização e a ocultação das diferenças e desigualdades entre as mulheres. Essas revisões decorrem da crescente tomada de consciência das diferenças e desigualdades no que concerne ao enquadramento político; à posição de classe; às circunstâncias raciais/étnicas; às distâncias de geração e ideológicas.

Do mesmo modo o conceito de Ubuntu torna-se um caminho necessário enquanto construtor de dignidade humana pautada pela experiência do Apartheid. Ressalto que tem sido através das lições mais dolorosas da escravidão que tomo o referido conceito como aprendizado. O pastor Desmond Tutu inscreve e traduz para o mundo o que é Ubuntu:

\begin{abstract}
Ubuntu é a essência do ser humano. Ele fala de como a minha humanidade é alcançada e associada à de vocês de modo insolúvel. Essa palavra diz, não como disse Descartes, "Penso logo existo", mas "Existo porque pertenço". Preciso de outros seres humanos para ser humano. O ser humano completamente autossuficiente é subhumano. Posso ser eu só porque você é completamente você. Eu existo porque nós somos, pois somos feitos para a condição de estarmos juntos, para a família. Somos feitos para a complementaridade. Somos criados para uma rede delicada de relacionamentos, de interdependência com os nossos companheiros seres humanos, com o restante da criação ${ }^{6}$.
\end{abstract}

Por acreditar na urgência de um modelo de comunidade que possa agregar a diversidade em que estamos localizados e as adversidades a que estamos também situados envolvidos por dinâmicas sociais e econômicas impostas pela elite dominante que insistentemente tenta forjar uma democracia racial — falha e desumana — onde o imperativo cor é flagrante para opressão e exclusão social.

6 TUTU, Desmond. (2013). Deus não é cristão e outras provocações. Rio de Janeiro: Thomas Nelson Brasil. 


\section{Cabelo crespo}

Há uns dois anos, desde que por acaso acessei o Coletivo Vício Cacheado nas redes sociais, observo o crescente número de grupos, comunidades, blog's e vlog's ${ }^{7}$ voltados para a temática que tem os cabelos como importante atributo de beleza e, mais especificadamente, os “cabelos crespos" e suas variáveis: cacheados, ondulados, crespos, enrolados e transinetes. Cabe dizer que as comunidades virtuais na temática voltada para cabelos crespos e naturais adotam termos particulares inseridos no "Dicionário das Cacheadas". Nesse caso, "transinete" é utilizado para distinguir as meninas/mulheres que estão na fase de transição do cabelo alisado para o cabelo natural, ou seja, são portadoras de duas texturas de fios: crespos na raiz e alisados nas pontas.

Figura 2 - Cabelos em fase "transinete"

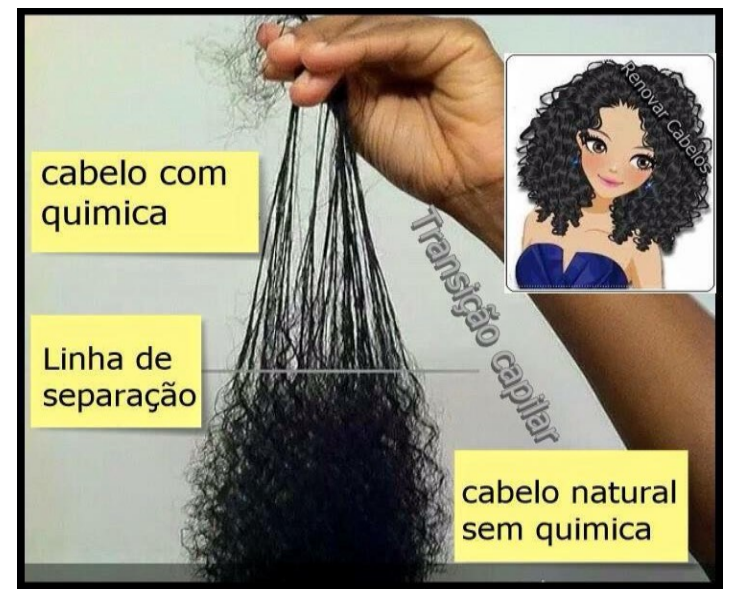

Fonte: Imagem disponível na Internet

Alguns desses grupos tratam a questão dos cabelos como apenas atributo de beleza e de uma estética mais natural, sem com isso enfatizar a questão identitária/racial. De fato, o que interessa nesse contexto é que há um movimento nacional que tem garantido vários encontros reunindo, na sua maioria, mulheres negras que discutem a partir do fim do uso das químicas alisadoras dos fios uma nova proposta de afirmação estética, na qual cabelos naturais sejam eles crespos; cacheados; ondulados; enrolados; transinetes e o Black Power passam a ter novos significados para a construção e reconstrução da imagem do "ser negra".

7 A grande diferença entre um vlog e um blog está mesmo no formato da publicação. Ao invés de publicar textos e imagens, o vlogger ou vlogueiro faz um vídeo sobre o assunto que deseja (ver: $<$ http://www.significados.com.br/vlog/>). 
Tabela 1 - Grupos virtuais que são distintos na referida temática

\begin{tabular}{|c|c|c|c|}
\hline COMUNIDADES & Membr@s & COMUNIDADES & Membr@s \\
\hline Vício Cacheado & 28.716 & Meninas Black Power & 54.952 \\
\hline Crespas e Cacheadas & 112 & $\begin{array}{l}\text { Cacheadas e Crespas pelo } \\
\text { Mundo }\end{array}$ & 16.971 \\
\hline Amigas Cacheadas & 57.458 & Cacheadas\&Estilosas & \\
\hline $\begin{array}{l}\text { Cabelo Afro - aprendendo } \\
\text { a cuidar }\end{array}$ & & $\begin{array}{l}\text { Cacheadas e Crespas de } \\
\text { Salvador }\end{array}$ & 13.528 \\
\hline Cacheadas de Maceió & 281 & Cacheadas da Tha & 1.722 \\
\hline Crespas TO & & Musas Cacheadas & 6.928 \\
\hline Cacheadas.com & 36.606 & Cacheadas de RO & 4.135 \\
\hline $\begin{array}{l}\text { Crespos \& Cacheadas po- } \\
\text { derosas }\end{array}$ & & Lar das Cacheadas & 3.989 \\
\hline Cacheadas Divas & & Beleza Cacheadas & 22.161 \\
\hline Cacheadas do Paraná & 952 & Cacheadíssimas & 6.531 \\
\hline Cacheadas se assumindo & 1919 & Cacheando em Salvador & 11.042 \\
\hline Cacheadas e Crespas de RO & & Manifesto Crespo & \\
\hline Cacheadas Coloridas & & Cacheando & 10.327 \\
\hline Cacheadas de Portugal & & Cacheadas & 18.133 \\
\hline $\begin{array}{l}\text { Amigas Cacheadas de Jo- } \\
\text { inville }\end{array}$ & & $\begin{array}{l}\text { Cabelos Cacheados e Cres- } \\
\text { pos }\end{array}$ & 93.089 \\
\hline Cacheadas em Transição & 135.923 & Cachos e Moda & \\
\hline Encrespa Geral & 13.140 & $\begin{array}{l}\text { Cabelos Afros, Crespos e } \\
\text { Cacheados }\end{array}$ & \\
\hline & & Cachos Alagoanos & 3.220 \\
\hline
\end{tabular}

Fonte: Facebook

Destaco que só busquei os grupos fechados, o que soma 37 grupos. Vemos que o número de membros participantes de algumas comunidades são surpreendentes. Destarte, nem todos têm o número atualizado, e outros não publicam. Entretanto, podemos estimar que mais de 600 mil mulheres estão inseridas nesse universo virtual que trata de "cabelos crespos", ressalto: é preciso considerar a participação de muitas mulheres em mais de um grupo o que não invalida a estimativa se considerarmos os vários grupos que não disponibilizam o seu número de membros.

O que é relevante para essa reflexão são as iniciativas que têm mobilizado esses grupos a saírem do virtual para adentrarem o real. O que estou dizendo é que a maioria desses grupos que são fechados tem ampliado suas investidas em encontros físicos, a fim de aproximar seus membr@s; realizar oficinas de cabelos, maquiagens e turbantes; debater temas associados à estética negra; propiciar o empreendedorismo negro; facilitar o acesso a produtos étnicos e apropriados para os cabelos crespos, cacheados e em transição; além de inaugurar um novo formato de lazer e sociabilidades. Levando em conta que são na sua maioria mulheres negras 
a se organizarem podemos crer tratar-se de arranjos diaspóricos comprometidas com o princípio Ubuntu de comunidade e fortalecimento do "sou porque somos".

Figura 3 - Fotos do acervo do Grupo Vício Cacheado

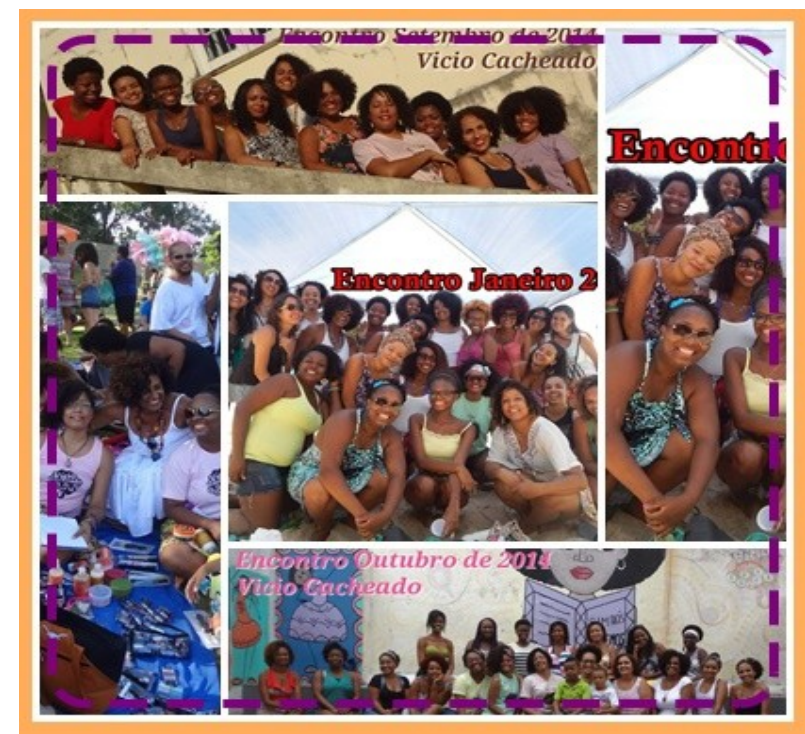

Fonte: acervo do Grupo Vício Cacheado

Normalmente, os encontros acontecem em espaços públicos, parques, jardins, arenas, studios de arte e oficinas alternativas. Avalio que esses grupos têm despertado um movimento político que gera renda, trabalho, diversão, arte, tecnologia e informação, além do sentimento de pertença que as mulheres passam a ter com a volta dos cabelos crespos e naturais. Ou seja, esse movimento estético afro-diaspórico cria e recria necessidades que o mercado precisa sanar e que o Estado deve atender através de políticas públicas de inclusão e diversidade. 
Figura 4 - Imagens disponibilizadas pela Internet

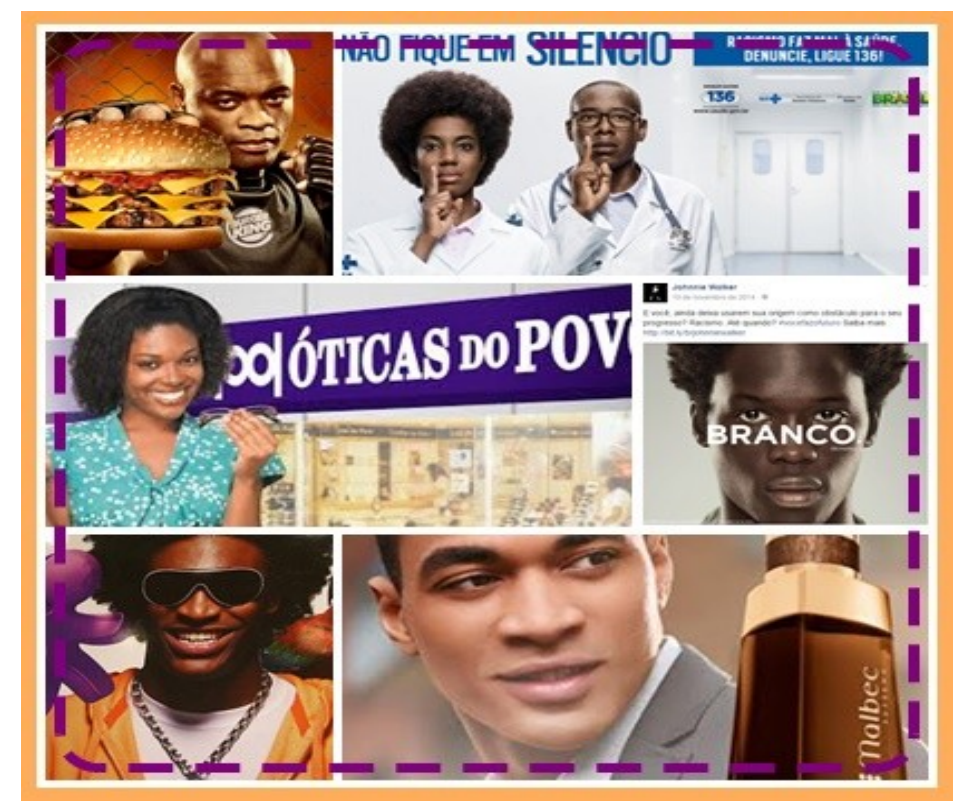

Fonte: Internet

É, portanto desse ponto de vista que analiso afirmativamente a presença negra na cena brasileira, exercendo cidadania insurgindo ao "estabelecido" empoderando-se.

\subsection{Empoderamento crespo}

A insurgência das mulheres negras em descolonizar uma estética capilar escrava dos alisamentos e das químicas agressivas faz com que a indústria de cosméticos, da propaganda e da beleza reveja seus conceitos. O conceito empoderamento torna-se o fio condutor desta nova discussão sobre afirmação estética onde o cabelo como signo de negritude deixa de ser um elemento negativo e se ressignifica na diáspora como impulsor do enfrentamento ao racismo. Empoderar nesse contexto é usar das ferramentas da tecnologia da informação nesse caso as redes sociais e fazer com que não só as mulheres negras mas outros atores sociais ampliem recursos e condições que lhes permitam ter voz, e maiores oportunidades de trocas entre os pares, alavancar novas capacidades de ação e decisão especialmente nos problemas que mais afetam suas vidas, em diversas situações seja na escola, no trabalho, nas instituições e repartições públicas bem como nos espaços de sociabilidades. Desse modo, entendo que o movimento de mulheres negras pelo empoderamento do cabelo crespo surge na contemporaneidade 
como um signo de apropriação de negritude anteriormente negado e silenciado pelo padrão branco de beleza.

Segundo a reportagem feita com a vice-diretora da Fundação Patrícia Galvão, em 2013:

De acordo com a pesquisa Representações das mulheres nas propagandas na TV, realizada pelo Data Popular e Instituto Patrícia Galvão, a maior parte dos entrevistados deseja que a diversidade da população feminina brasileira esteja mais representada: $51 \%$ gostariam de ver mais mulheres negras e $64 \%$ gostariam de mais mulheres de classe popular nas propagandas. A pesquisa realizou 1.501 entrevistas com homens e mulheres maiores de 18 anos, em 100 municípios de todas as regiões do país, entre os dias 10 e 18 de maio deste ano (http://agenciapatriciagalvao.org.br/).

É interessante fazer esse percurso para demonstrar estatisticamente como, durante décadas, as "caras pretas" estiveram fora da cena brasileira. Invariavelmente, homens e mulheres negros sempre foram representados no contexto da mídia como subalternos, seja nas propagandas, nas novelas, nos seriados e filmes: os personagens são sempre pobres, sem escolarização, engraçados, alcoólatras e sem referências de "família".

Na verdade, não há muitos estudos sobre o negro na publicidade brasileira. Pesquisa
feita durante 20 anos (1985-2005) pelo professor Carlos Augusto Martins, mestre
em comunicação pela USP, concluiu que os brancos interpretam todos os tipos de
personagens, mas poucos negros conseguem fugir de cinco estereótipos na publici-
dade na TV (trabalhador braçal, por exemplo). Ainda assim, a pesquisa mostra evo-
lução. Em 1985, havia 3\% de anúncios com negros. Em 2005, este percentual subiu
para 13\%. De qualquer forma, lembra Martins, "é muito pouco se a gente pensar na
realidade populacional do Brasil" (www.gazetadopovo.com.br).

Procuro fazer o contraponto apresentando o fenômeno dos grupos virtuais voltados para os cabelos crespos e naturais como um dos indicadores de reversão dos estereótipos postulados pela mídia brasileira sobre homens e mulheres negras. Ressalto que minha análise não se esgota, e não confirma o fim dos estereótipos nem mesmo do racismo praticado contra os negros no Brasil. Identifico a partir dos meus estudos e das vivências no contexto dos encontros de algumas comunidades virtuais que há uma inserção, mesmo que timidamente, das "caras pretas" na cena brasileira, e certamente o fenômeno do empoderamento dos cabelos crespos e naturais tem influenciado substancialmente o olhar sobre a estética negra.

Destaco, que entre essas mulheres negras algumas expressam seus desejos sobre a mudança dos cabelos interessadas na redução de danos dos fios e do custo/benefício não mencionando que o fazem em detrimento de uma afirmação de negritude. Observo que ainda que o objetivo não seja identitário de raça essas mulheres terminam por somar o contingente de crespas e cacheadas o que invariavelmente influência o senso comum a perceber essas presenças remetendo-os a um outro olhar. 
Figura 5 - Imagens de acervo da Comissão da Marcha do Empoderamento Crespo

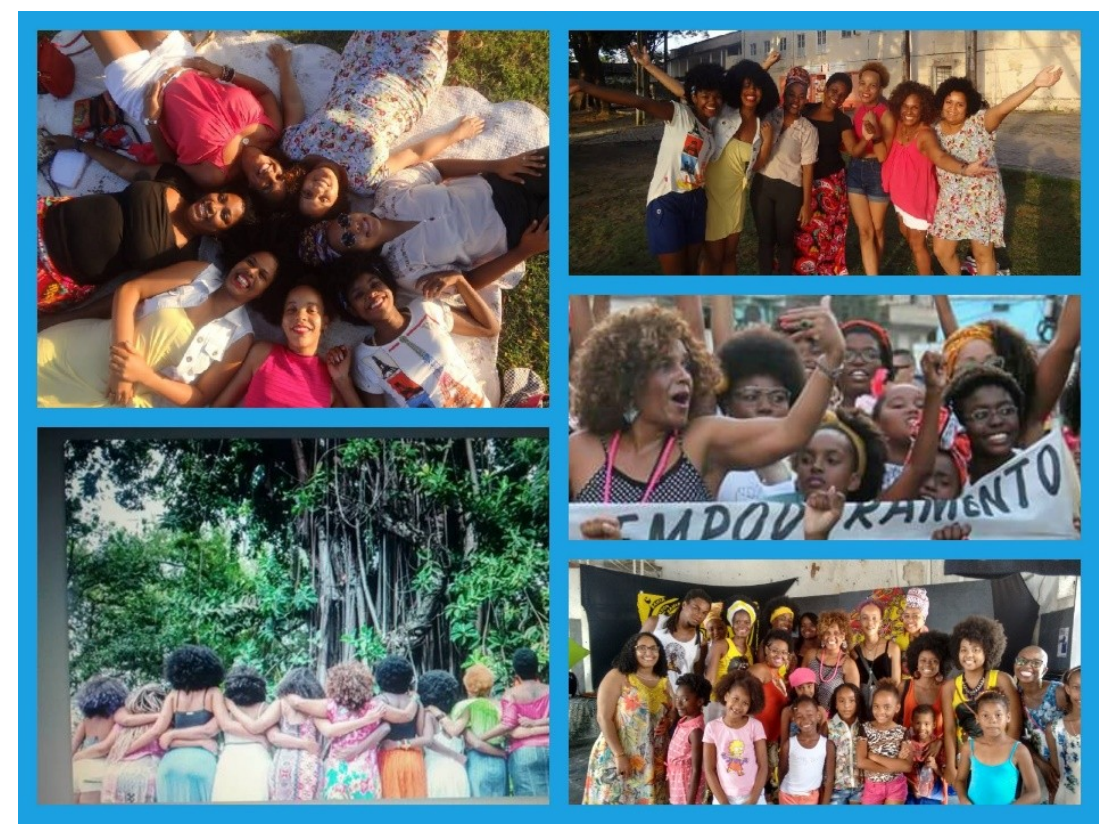

Atentemo-nos ao título desse artigo, reconhecendo como esse movimento tem sido determinante na construção de uma estética política, cultural e Afirmativa, anunciando que essas presenças serão cada vez mais catalizadoras de autoestima e consequente empoderamento. $\mathrm{O}$ padrão de beleza eurocêntrico não nos representa e nem é mais o único definidor de status quo. Não tem mais como negar que as mulheres negras estão no front da luta antirracista e que a Marcha do Empoderamento ocorrida em Salvador no dia 07 de novembro de 2015 mobilizou um número expressivo ( 3 mil) de jovens, homens, mulheres e crianças que juntos deram um largo passo numa caminhada que tem história rumo a revolução negra e crespa necessária para a equidade e fim da discriminação racial que mata nossos jovens todos dias fisicamente identificados inicialmente pela cor e pelo crespo do cabelo. A Marcha do Empoderamento Crespo de Salvador hoje se reconhece como um coletivo de mulheres negras autoorganizadas, cientes do papel e da missão a que estão se propondo, dentre elas o enfrentamento a luta contra o genocídio da juventude negra; igualdade de oportunidade para mulheres negras; atendimento humanizado nos sistemas de saúde; fortalecimento da rede de apoio ao portadores da anemia falciforme; pelo fim da violência e pelo reconhecimento do cabelo crespo como signo de identidade. 


\section{Considerações finais}

O estigma da cor da pele e dos cabelos crespos tem sido paulatinamente debatido nas redes sociais. O uso desta tecnologia tem favorecido singularmente a expansão de comunidades voltadas para a questão racial, entre outras bandeiras, apesar de ser também o meio pelo qual vêm se materializando as diversas formas de racismo - entre eles contra a estética negra de reconhecidos personagens da cena brasileira e também de anônimos por vezes rechaçados com comentários preconceituosos e racistas. Assim, não tenho a pretensão de ocultar a realidade do racismo brasileiro; ao contrário: a luta é diária. E percebendo o alcance das redes sociais me proponho a interagir com esse meio tecnológico para ampliar o debate sobre a nova ordem do dia: A estética afro-diaspórica como marcadora das transformações do padrão estético normativo e do Empoderamento Crespo. Enfim tomando os cabelos crespos como signo de reparação dos negros na diáspora, eleva-se a autoestima, deixamos de olhar para os pés e passamos a olhar o que está a nossa frente sem envergadura da coluna.

Digo, somos conscientes que o que nos leva a insurgir esteticamente está no confronto do olhar do outro sobre nós; olhar impregnado de um juízo de valor estético pautado no padrão branco. A partir do momento que decidimos não mais abaixar o volume dos nossos cabelos estamos assumindo um novo comportamento - uma postura crítica e efetivamente uma estética afirmativa.

\section{Referências}

COSTA, Sergio. Dois Atlânticos. Teoria Social, anti-racismo, cosmopolitismo. Belo Horizonte: UFMG, 2006.

COSTA, Suely G. Feminismos No Brasil. Revista Estudos Femininos, Florianópolis, v. 12, set./dez. 2004.

DÁVILA, Jerry. Diploma de brancura. Política Racial no Brasil - 1917-1945. Tradução Claudia Sant'Ana Martins. São Paulo: UNESP, 2006.

FLORES, Maria B. Ramos. Tecnologia e estética do racismo. Ciência e arte na política da beleza. Chapecó: Argos, 2007.

FOUCAULT, Michel. Microfísica do poder. 11. ed. Rio de Janeiro: Graal, 1997.

GOMES, Naira. Transição Capilar - Sobre o que vai na cabeça das mulheres em Salvador. Salvador: Monografia, UFBA, 2015. 
MARTINS, Carlos Augusto. O negro na propaganda. Disponível em:

$<$ www.revistaafro.com.br>. Acesso em: 11 jun. 2015.

MATTOS, Ivanilde Guedes de. Estética afirmativa: o corpo negro e o ensino de Educação Física. Salvador: EDUNEB, 2009.

MATTOS, Wilson Roberto de. Negros contra ordem: astúcias, resistências e liberdades possíveis (Salvador 1850-1888). Salvador: EDUNEB; EDUFBA, 2008.

SOUZA. Elizeu C. A arte de contar e trocar experiências: reflexões teórico-metodológicas sobre história de vida em formação Elizeu Clementino de Souza. Revista Educação em Questão, Natal, v. 25, n. 11, p. 22-39, jan./abr. 2006.

\section{Sites}

Entrevista sobre negros na propaganda brasileira. http://agenciapatriciagalvao.org.br/mulhere-midia/pautas-midia/mulher-negra-e-invisivel-na-publicidade/(Luciana Araújo/Agência Patrícia Galvão, 23/09/2013) Acessado em 14.07.2015.

Negros estão em menos de $10 \%$ das propagandas. In: <www.gazetadopovo.com.br $>$ de 14/08/2008. Acesso em 08/07/2015.

ubuntu-uma-perspectiva-africana-sobre-etica-e-dignidadehumana.In:http://www.ihu.unisinos.br/noticias/noticias. Acesso em 15/08/2015.

http://www.correio24horas.com.br/detalhe/noticia/marcha-do-empoderamento-crespo-reunecerca-de-tres-mil-pessoas-em-salvador/?cHash=dc177de4b853489f697d9d8a69f0b5f4.

Recebido em 4 de agosto de 2015.

Aceito em 12 de setembro de 2015. 
